\title{
Does exercise addiction exist? A brief review on current measurement tools and future directions
}

\author{
Flora Colledge ${ }^{1 *}$, Ursula Gisela Buchner ${ }^{2}$, André Schmidt ${ }^{3}$ and Marc Walter ${ }^{3}$ \\ ${ }^{1}$ Department of Sport, Exercise and Health, University of Basel, Birsstrasse 320b, 4052 Basel, Switzerland \\ ${ }^{2}$ Department of Health, German University of Health and Sport, Steinheilstraße 4, D-85737, Ismaning, Germany \\ ${ }^{3}$ University Psychiatric Clinics, University of Basel, Wilhelm Klein Strasse 27, 4056 Basel, Switzerland
}

\begin{abstract}
Exercise addiction is a term gaining widespread use in the scientific literature and popular press. However, despite numerous studies of risk factors and affected groups, there is no consensus on how the term should be defined. More importantly, it remains unclear whether problematic exercise habits should be categorised as a behavioral addiction at all, or whether the symptoms are better understood as occurring in the course of other psychiatric disorders. A brief review highlights the large impact that cross-sectional questionnaire-based research has had in this field and suggests an approach to more reliably categorizing problematic exercise as either a disorder or a symptom cluster.
\end{abstract}

\section{Introduction}

The possibility that humans may become addicted to exercise was first posited by Baekeland, who noted that participants in a study on sleep, who were ostensibly supposed to avoid doing exercise, found it extremely difficult to abstain from their usual physical activity [1]. While Glasser categorized exercise, specifically running, as a "positive" addiction that is part of a healthy life, reports that exercise could have negative, as well as positive, effects on humans were soon published in the medical literature [2]. Morgan reported that exercise could constitute a specifically "negative" addiction, citing compulsion to exercise and the appearance of unpleasant withdrawal symptoms as evidence for the detrimental effects of this condition [3]. Leaving aside the question of whether any addiction, as defined by the DSM-5, could be seen as "positive", and despite numerous case reports, it is currently the case that exercise addiction is a widely discussed, but insufficiently defined concept [4-6].

A widely recognized issue is that prevalence rates of risk for exercise addiction have been reported at between $0.3 \%$ and $52 \%[7,8]$. While the lower estimates are typically of general populations, and the higher estimates of potentially "at risk" groups such as triathletes and gymgoers, figures of between $3 \%$ and $45 \%$ for "college students", or $26 \%$ of participants in a short recreational race, appear highly counterintuitive [8-12]. These variations and at times startlingly high prevalence rates may be explained, in part, by the nature of the instruments used to assess exercise addiction. In the absence of a consensus about behavioral addictions in general, and exercise addiction in particular, existing questionnaires must essentially either copy substance use disorder tools or employ a list of theory-based items [13]. In both cases, the absence of thorough background descriptions of the course and characteristics of exercise as an addictive disorder mean that assessing predictive and ecological validity of these measures is challenging, and has never, to our knowledge, been attempted.

Case studies and research reports on exercise addiction typically document the experiences of individuals who feel they have lost control of their exercise behavior [14-19]. The symptoms are frequently described, by the sufferer and/or the author, as mirroring symptoms of a substance use disorder. For example, an increase in the amount of exercise the person requires to feel satisfied indicates tolerance, continuing to exercise through illness or injury indicates persistence despite understanding of negative consequences, and feelings of anxiety and negative affect when abstaining from exercise indicate withdrawal $[20,21]$. However, exercise addiction is not currently included as a nonsubstance related disorder in the DSM-5, as the evidence for a clear categorization is considered to be too weak [22]. This can be attributed to three main factors; uncertainty about the degree to which typically healthy behaviors, such as exercise or sex, can be classed as addictions, overlap with other psychiatric disorders, particularly eating disorders [24] and a remarkably large variance in prevalence estimates from a number of existing studies [13,23,24].

This variance in prevalence estimates may be an indication that the measurement of exercise addiction is problematic. The aim of this brief review is therefore to report on the measurement instruments currently in use in this field, and to offer suggestions about what remains to be done to clarify outstanding questions regarding exercise addiction.

\section{Methods}

As the construct of exercise addiction is not satisfactorily defined, the contents of the questionnaires used to assess it should be considered carefully. A variety of questionnaires currently form the evidence basis on which future decisions about the nature of exercise addiction will ultimately be made, so a close scrutiny of their structure is important.

${ }^{*}$ Correspondence to: Flora Colledge, Departement für Sport, Bewegung und Gesundheit, Birsstrasse 320b Basel 4052, Switzerland, Tel: 00416120747 87; E-mail: flora.colledge@unibas.ch

Key words: exercise, exercise addiction, behavioral addiction, review

Received: March 29, 2019; Accepted: April 05, 2019; Published: April 08, 2019 
To this end, we aimed to identify the frequency with which the various measurement instruments are employed in the current literature on exercise addiction. A search of the PubMed and Web of Knowledge databases using the terms "exercise addiction", "exercise dependence", "compulsive exercise" and "obligatory exercise" was carried out. We employed no date restrictions, searched in English language only, excluded validation studies, and excluded studies with another condition (depression, eating disorder) as the primary disorder under investigation. A PRISMA flow chart indicating the results of the search and studies included is presented in Figure 1 [25].

\section{Results}

79 studies were included in our brief assessment. Of these, 27 used the Exercise Dependence Scale (EDS), 25 used the Exercise Addiction Inventory (EAI), 12 used the Compulsive Exercise Test (CET), 8 used the Exercise Dependence Questionnaire (EDQ), and 6 used the Obsessive Exercise Questionnaire (OEQ). 9 studies used multiple questionnaires to assess exercise addiction; the distribution is presented in Figure 2. When the numbers from studies using multiple instruments are included, three instruments (EDS, EAI, CET) account for over $80 \%$ of the published studies. The distribution is illustrated in Figure 2. With two exceptions, all studies were cross-sectional $[26,27]$.

\section{Psychometric properties of measurement tools}

The EDS is a 21-item measure based on 7 DSM-IV criteria for substance dependence, namely withdrawal, continuance, tolerance, loss of control, reduction of other activities, time spent in the behavior, and intentionality [21]. While a sum score is used to indicate exercise dependence symptoms (higher score $=$ higher risk), respondents can also be categorized into risk groups based on their responses to questions about particular symptoms. The EDS has been shown to have good internal consistency, with the coefficient alpha between 0.78 and 0.92 for the 7 subscales, and support for its convergent validity has also been shown $(\mathrm{p}=0.01)[28,29]$.

The EAI is a six-item questionnaire which operationalizes exercise addiction based on six symptoms identified by Griffiths in a case study of an individual with extreme exercise habits [10]. Incentive salience, mood modification, tolerance, withdrawal, conflict and relapse are each addressed with one item, expressly intended to enable brief assessments of at-risk individuals. A score of 24 or more is considered the cut-off for "at-risk" individuals. An analysis of the psychometric properties of the EAI indicated good internal consistency (Cronbach $\alpha=0.84$ ), while principal component analysis indicated that the questionnaire items represent a single component with explains $55.9 \%$ variance. A

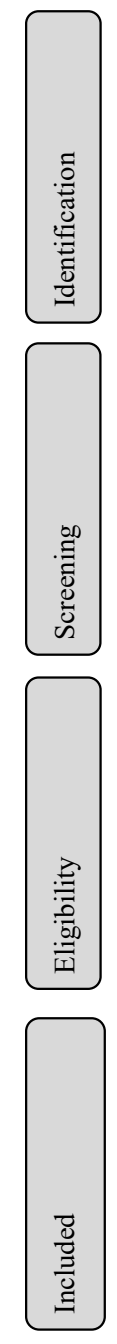

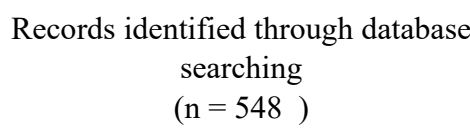

Additional records identified through other sources

$$
(\mathrm{n}=0)
$$

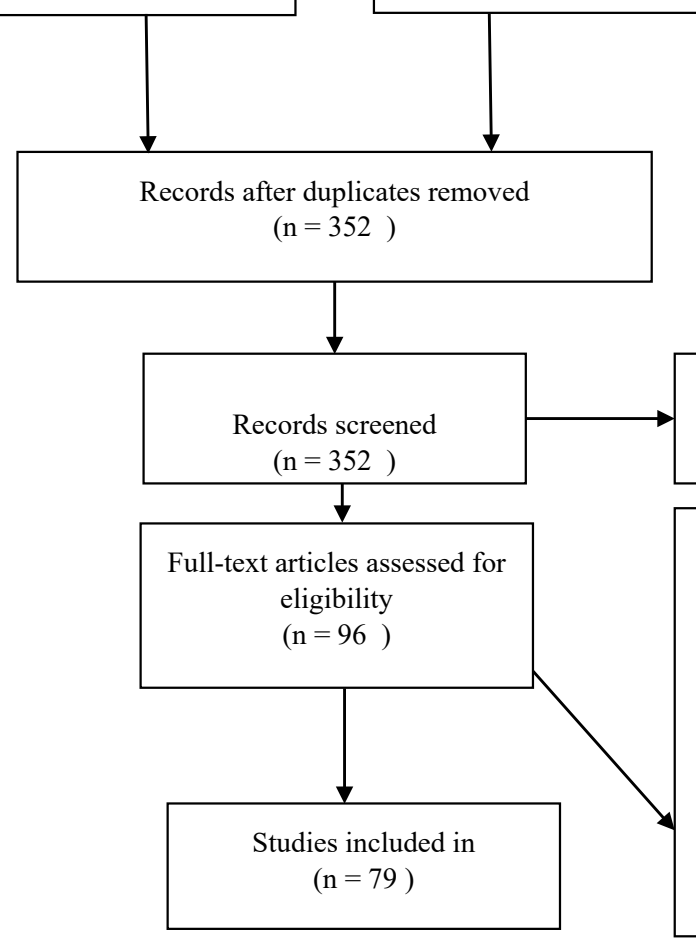

Records excluded $(\mathrm{n}=38)$

Full-text articles excluded

$$
(\mathrm{n}=17)
$$

Reasons: other disorder as primary focus $(n=9)$

No questionnaire employed $(\mathrm{n}=3)$

Foreign language $(n=5)$ 


\section{Distrubution of questionnaires}

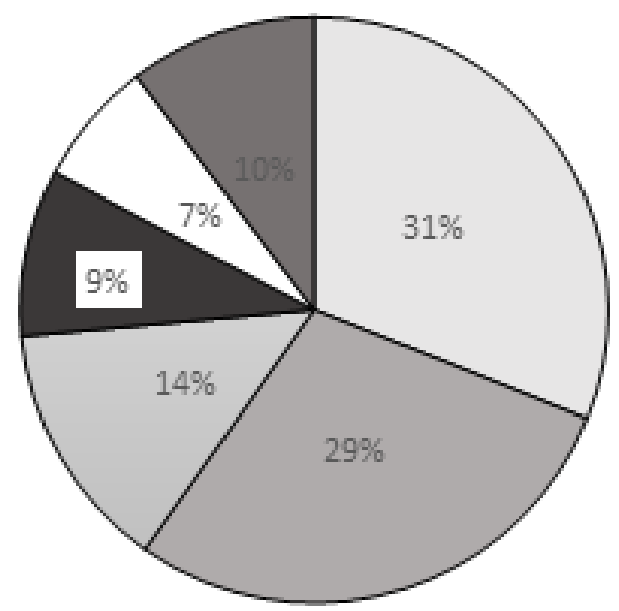

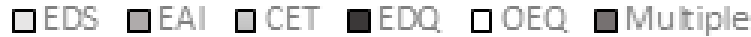

Figure 2. Distribution of questionnaires identified in a review of studies on exercise addiction

Note: EDS: Exercise Dependence Scale; EAI: Exercise Addiction Inventory; CET: Compulsive Exercise Test; EDQ: Exercise Dependence Questionnaire; OEQ: Obsessive Exercise Questionnaire

subsequent study with a population of Crossfit athletes indicated that the six items explained $42.6 \%$ of the variance and had a Cronbach's a 0.73 [30].

The CET is a 25 -item measure specifically designed for research related to eating disorders [31]. The measure is "based on a cognitivebehavioral conceptualisation of excessive exercise." A higher sum score indicates higher level of compulsive exercise. An initial validation showed a Cronbach's $\alpha$ of 0.85 , with a subsequent study in an adolescent population yielding a value of 0.88 [32].

While each of these instruments is based on sound theoretical underpinnings, and has acceptable psychometric properties, it remains the case that their use has yielded somewhat surprising results in certain studies [13]. First, it must be noted that each of the three instruments uses a different theoretical approach to defining the construct of exercise addiction, so the body of literature on this issue as a whole is heterogeneous. Second, each of the questionnaires contains items, which are likely to be scored highly by individuals who are extremely dedicated to exercise and sport for professional or amateur competitive reasons. While speculative, we suggest that this may explain some of the high prevalence rates captured in certain studies, particularly those carried out in athletic populations [33]. It is certainly not inconceivable that an athlete with few family commitments who takes his or her athletic goals very seriously could exceed the cut-offs of these questionnaires [34]. The questionnaires themselves are clearly described by their authors as indicators of risk, not diagnostic instruments, and therefore may rightly include items- which are somewhat vague in their formulation. However, when such instruments form the basis of the evidence on a given phenomenon, furthering understanding of the nature of exercise addiction is challenging. This is not to diminish the instruments, or studies to date, which employ them; these arguably serve the very valuable purpose of demonstrating that a number of people appear to have a troubled relationship with exercise. Based on this, a concrete approach to better characterize exercise addiction is now required. In particular, we suggests the following recommendations:

\section{Recommendations for future research}

- A comprehensive list of terms used in the literature that are broadly synonymous with "exercise addiction" should be compiled. This will ensure exhaustive searches on this topic in future studies.

- A comprehensive list of symptoms reported in case studies and qualitative studies should be gathered. This list may be expanded by subsequent studies but should serve as a foundation for understanding of whether exercise addiction appears to fit the DSM- 5 criteria for non-substance related disorders. Each symptom should be characterized in as much detail as possible (i.e. include motivations, attitudes to exercise, daily habits surround exercise, etc.)

- Researchers should carefully consider whether existing questionnaires for assessing risk for exercise addiction fit their aims of their study.

- Questionnaires, which can reliably differentiate between professional and passionate athletes, and individuals who are burdened by their exercise behaviors, must be developed. These questionnaires should also be appropriate for a variety of exercise and sport types in different settings.

- Screenings with individuals who report symptoms of exercise addiction should be conducted, to assess whether, and to what extent, it is comorbid with psychiatric disorders such as substance use disorder, depression or schizophrenia. It must be clarified whether symptoms of exercise addiction represent a distinct category, or whether certain symptoms are shared across psychiatric nosologies. For instance, many psychiatric disorders are characterized by motivational impairments that might contribute to altered mood states [35-37]. In particular, it has been shown that deficits in reward processing are linked to depressive symptoms in patients with schizophrenia, alcohol dependence, major depressive disorder, bipolar disorder or attention deficit/hyperactivity disorder [38]. Intriguingly, impaired reward processing was related to reduced activation in the ventral striatum across diagnostic boundaries, indicating a common neural mechanism for depressive symptoms. Hence, it will be interesting to see whether exercise addiction is also associated with ventral striatum related depressive symptoms as seen in many other psychiatric disorders. Along the same vein, impulsivity is a core symptom in various psychiatric disorders including addictive disorders, which is triggered via altered activation in prefrontal brain regions, especially the inferior frontal gyrus [39-40]. It will be revealing to see whether exercise addiction is also accompanied by prefrontal cortex mediated impulsivity like in several other psychiatric disorders.

- On the basis of these screenings, evidence should be compiled for and against the suggestion that exercise addiction is not a distinct form of behavioral addiction, but rather a symptom (or symptom cluster) which sometimes emerges in the course of other disorders. In line with Cook, Hausenblas and Freimuth, a clearer delineation between the compulsive, addictive or physical dependency elements of the phenomenon should also be elaborated [41].

\section{Conclusion}

Despite numerous studies examining the phenomenon of a possible exercise addiction, a thorough characterization is still required. An understanding of the circumstances in which symptoms develop and escalate, and a psychiatric portrait of those who report symptoms will go a long way to providing evidence which sheds more light on 
whether exercise can be classified as a behavioral addiction. As a final consideration, it is worth emphasizing that even if exercise addiction is not a form of behavioral disorder, its symptoms, like those of personality disorders, can still influence and complicate the treatment of psychiatric diagnoses [42]. It is therefore important that more clarity about the extent of exercise addiction symptoms is provided.

\section{References}

1. Baekeland F (1970) Exercise deprivation: Sleep and psychological reactions. Arch Gen Psychiatry 22: 365-369. [Crossref]

2. Glasser W (1976) Positive addiction. Oxford, England: Harper \& Row.

3. Morgan WP (1979) Negative Addiction in Runners. Phys Sportsmed 7: 55-77. [Crossref]

4. American Psychiatric Association (2013) Diagnostic and Statistical Manual of Mental Disorders (DSM-V) (5th ed.). Washington, DC: American Psychiatric Association.

5. Nogueira A, Molinero O, Salguero A, Márquez S (2018) Exercise Addiction in Practitioners of Endurance Sports: A Literature Review. Front Psychol 9: 1484. [Crossref]

6. Szabo A, Griffiths MD, de La Vega Marcos R, Mervó B, Demetrovics Z (2015) Methodological and Conceptual Limitations in Exercise Addiction Research. Yale $J$ Biol Med 88: 303-308. [Crossref]

7. Lichtenstein MB, Nielsen RO, Gudex C, Hinze CJ, Jorgensen U (2018) Exercise addiction is associated with emotional distress in injured and non-injured regular exercisers. Addict Behav Rep 8: 33-39. [Crossref]

8. Bruno A, Quattrone D, Scimeca G, Cicciarelli C, Romeo VM, et al. (2014) Unraveling exercise addiction: the role of narcissism and self-esteem. $J$ Addict 2014: 987841. [Crossref]

9. Leone JE, Sedory EJ, Gray KA (2005) Recognition and treatment of muscle dysmorphia and related body image disorders. J Athl Train 40: 352-359. [Crossref]

10. Griffiths MD, Szabo A, Terry A (2005) The exercise addiction inventory: a quick and easy screening tool for health practitioners. British Journal of Sports Medicine 39: e30.

11. Zmijewski CF, Howard MO (2003) Exercise dependence and attitudes toward eating among young adults. Eat Behav 4: 181-195. [Crossref]

12. Sudi K, Ottl K, Payerl D, Baumgartl P, Tauschmann K, et al. (2004) Anorexia athletica. Nutrition 20: 657-661. [Crossref]

13. Monok K, Berczik K, Urban R, Szabo A, Griffiths MD, et al. (2012) Psychometric properties and concurrent validity of two exercise addiction measures: A population wide study. Psychology of Sport and Exercise 13: 739-746.

14. Anandkumar S, Manivasagam M, Kee VTS, Meyding-Lamade U (2018) Effect of physical therapy management of nonspecific low back pain with exercise addiction behaviors: A case series. Physiother Theory Pract 34: 316-328. [Crossref]

15. Vitale C, Santangelo G, Verde F, Amboni M, Sorrentino G, et al. (2010) Exercise dependence induced by pramipexole in Parkinson's Disease-a case report. Mov Disord 25: 2893-2894. [Crossref]

16. Griffiths M (1997) Exercise Addiction: A Case Study. Addiction Research 5: 161-168.

17. Hausenblas HA, Schreiber K, Smoliga JM (2017) Addiction to exercise. BMJ 357: 1745. [Crossref]

18. Lichtenstein MB, Christiansen E, Elklit A, Bilenberg N, Støving RK (2014) Exercise addiction: A study of eating disorder symptoms, quality of life, personality traits and attachment styles. Psychiatry Research 215: 410-416. [Crossref]

19. Spieker MR (1996) Exercise dependence in a pregnant runner. J Am Board Fam Pract 9: 118-121. [Crossref]

20. Freimuth M, Moniz S, Kim SR (2011) Clarifying Exercise Addiction: Differential Diagnosis, Co-occurring Disorders, and Phases of Addiction. Int J Environ Res Public Health 8: 4069. [Crossref]
21. Hausenblas HA, Symons Downs D (2002) Exercise dependence: a systematic review. Psychology of Sport and Exercise 3: 89-123.

22. Potenza MN (2014) Non-substance addictive behaviors in the context of DSM-5. Addict Behav 39: 1-2. [Crossref]

23. Billieux J, Schimmenti A, Khazaal Y, Maurage P, Heeren A (2015) Are we overpathologizing everyday life? A tenable blueprint for behavioral addiction research. $J$ Behav Addict 4: 119-123. [Crossref]

24. Bamber DJ, Cockerill IM, Rodgers S, Carroll D (2003) Diagnostic criteria for exercise dependence in women. Br J Sports Med 37: 393-400. [Crossref]

25. Moher D, Liberati A, Tetzlaff J, Altman DG, The PG (2009) Preferred Reporting Items for Systematic Reviews and Meta-Analyses: The PRISMA Statement. PLoS Medicine 6: e1000097. [Crossref]

26. Elbourne KE, Chen J (2007) The continuum model of obligatory exercise: a preliminary investigation. J Psychosom Res 62: 73-80. [Crossref]

27. Goodwin H, Haycraft E, Meyer C (2014) Sociocultural risk factors for compulsive exercise: a prospective study of adolescents. Eur Eat Disord Rev 22: 360-365. [Crossref]

28. Hausenblas H, Downs D (2002) How Much is Too Much? The Development and Validation of the Exercise Dependence Scale. Psychol Health 17: 387-404.

29. Symons Downs D, Hausenblas H, Nigg, C (2004) Factorial Validity and Psychometric Examination of the Exercise Dependence Scale-Revised. Measurement in Physical Education and Exercise Science 8: 183-201.

30. Lichtenstein M, Jensen T (2016) Exercise addiction in CrossFit: Prevalence and psychometric properties of the Exercise Addiction Inventory. Addict Behav Rep 3: 33-37.

31. Taranis L, Touyz S, Meyer C (2011) Disordered eating and exercise: Development and preliminary validation of the compulsive exercise test (CET). Eur Eat Disord Rev 19: 256-268. [Crossref]

32. Goodwin H, Haycraft E, Taranis L, Meyer C (2011) Psychometric evaluation of the compulsive exercise test (CET) in an adolescent population: links with eating psychopathology. Eur Eat Disord Rev 19: 269-279.

33. Cook B, Karr TM, Zunker C, Mitchell JE, Thompson R, et al. (2013) Primary and secondary exercise dependence in a community-based sample of road race runners. $J$ Sport Exerc Psychol 35: 464-469. [Crossref]

34. Di Lodovico L, Poulnais S, Gorwood P (2018) Which sports are more at risk of physical exercise addiction: A systematic review. Addict Behav pii: S0306-4603. [Crossref]

35. Bjork JM, Smith AR, Chen G, Hommer DW (2012) Mesolimbic recruitment by nondrug rewards in detoxified alcoholics: effort anticipation, reward anticipation, and reward delivery. Hum Brain Mapp 33: 2174-2188. [Crossref]

36. Knutson B, Bhanji JP, Cooney RE, Atlas LY, Gotlib IH (2008) Neural responses to monetary incentives in major depression. Biol Psychiatry 63: 686-692. [Crossref]

37. Nielsen MO, Rostrup E, Wulff S, Bak N, Lublin H, et al. (2012) Alterations of the brain reward system in antipsychotic naive schizophrenia patients. Biological Psychiatry 71 898-905. [Crossref]

38. Hagele C, Schlagenhauf F, Rapp M, Sterzer P, Beck A, et al. (2015) Dimensional psychiatry: reward dysfunction and depressive mood across psychiatric disorders. Psychopharmacology (Berl) 232: 331-341. [Crossref]

39. Moeller FG, Barratt ES, Dougherty DM, Schmitz JM, Swann AC (2001) Psychiatric aspects of impulsivity. Am J Psychiatry 158: 1783-1793. [Crossref]

40. McTeague LM, Goodkind MS, Etkin A (2016) Transdiagnostic impairment of cognitive control in mental illness. J Psychiatr Res 83: 37-46. [Crossref]

41. Cook B, Hausenblas H, Freimuth M (2014) Exercise addiction and compulsive exercising: Relationship to eating disorders, substance use disorders, and addictive disorders. In Eating disorders, addictions and substance use disorders: Research, clinical and treatment perspectives. (pp. 127-144). New York, NY, US: SpringerVerlag Publishing.

42. Morse JQ, Pilkonis PA (2007) Screening for personality disorders. J Pers Disord 21: 179-198. [Crossref]

Copyright: (C2019 Colledge F. This is an open-access article distributed under the terms of the Creative Commons Attribution License, which permits unrestricted use, distribution, and reproduction in any medium, provided the original author and source are credited. 